\title{
Journal of Science and Engineering
}

\section{DUKUNGAN MODA TRANSPORTASI UDARA DALAM PENGEMBANGAN KAWASAN INDUSTRI BULI KABUPATEN HALMAHERA TIMUR}

\author{
Muhammad Rizala ${ }^{a}$, Firdawaty Marasabessyb ${ }^{\mathrm{b}}$,Edward Rizky \\ Ahadian $^{c}$, Siti Aulia Ramadhani ${ }^{\mathrm{d}}$ \\ a,b,c Universitas Khairun, Ternate, Indonesia
}

Article history

Received

8 September 2018

Received in revised form

5 Oktober 2018

Accepted

10 Okotober 2018

*Corresponding author adams.rizal@yahoo.co.id

\section{Graphical abstract}

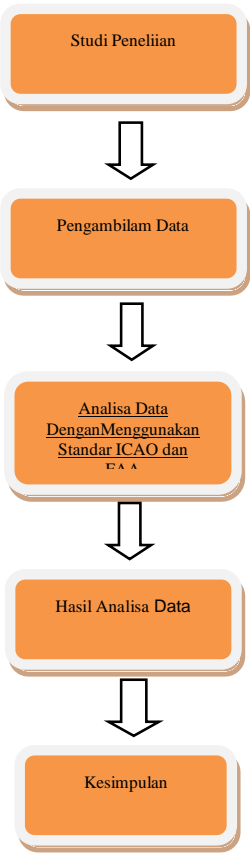

\begin{abstract}
District East Halmahera in North Maluku, is district now become one of industrial estate which was developed by Ministry of Industry. A Plan to make as one of Industrial area and this thing also had an influence on the performance of the air transportation, in the Buli airport on East Halmahera which currently categorized as class iii airport with kind of aircraft operating of ATR 72-600 so that is considered need to be improved the ability of its service in order to statisfy the demand for which it will follow and also have economic growth and regional development. The purpose of this research to know the number of passengers who will use the Buli Airport in the year 2032, know the number of the frequency of flight in the year plan such as in 2032. And knowing the dimension of the airside facilities include the runway, taxiway, and apron in accordance with plan of the Boing 737-500. From the data obtained we could predict at a later date how can the forecasting and demand that will happen. From the data can were analysed by using three (3) method of analysis as Linear trend, Kuadratis, and Exponensial. And from the result of the analysis taken the best trend based on the Sum Of Square Error (SSE) to estimate the number of passenger as many as 50548 soul. While obtained the number of planes as many as 861 a plane with the movement of as much as two the movement of daily. The result points to the need to design the addition of runway being $2600 \mathrm{~m}$, taxiway $152 \times 15 \mathrm{~m}$, and sidening of an apron 105 x $67 \mathrm{~m}$. The result of design inclosed.
\end{abstract}

Keywords: airport, Runway, Taxiway, Apron

\section{Abstrak}

Kabupaten Halmahera Timur Provinsi Maluku Utara merupakan kabupaten yang saat ini menjadi salah satu Kawasan Industri yang sedang di kembangkan oleh Kementrian Perindrustrian. Dengan dijadikannya sebagai salah satu kawasan industry maka hal itu juga berpengaruh terhadap kinerja perhubungan udara, yaitu pada Bandar Udara Buli Kab. Halmahera Timur yang saat ini tergolong sebagai bandara kelas III dengan jenis pesawat yang beroperasi ATR 72-600 sehingga dianggap perlu untuk ditingkatkan kemampuan pelayanannya agar dapat memenuhi permintaan yang akan datang serta ikut menunjang pertumbuhan perekonomian dan perkembangan daerah. Tujuan penelitian ini untuk mengetahui jumlah penumpang yang akan menggunakan Bandar Buli pada tahun 2032, mengetahui jumlah frekuensi penerbangan pada tahun rencana yaitu tahun 2032, dan mengetahui dimensi fasilitas sisi udara meliputi runway, taxiway, dan apron, sesuai dengan pesawat rencana B 737-500. Dari data-data yang diperoleh, kita dapat memperkirakan dikemudian hari bagaimana ramalan dan permintaan (Forecast and demand) yang akan terjadi. Dari data-data tersebut dapat dianalisa dengan menggunakan tiga (3) metode analisi Trend seperti Linear, Kuadratis, dan Eksponensial. Dari hasil analisa diambil trend terbaik berdasarkan Sum Of Square Error untuk memperkirakan jumlah penumpang pada tahun 2032 dan diperoleh jumlah penumpang sebanyak 50548 jiwa. Sedangkan diperoleh jumlah pesawat sebanyak 861 pesawat dengan pergerakan harian sebanyak 2 pergerakan. Hasil desain menunjukkan perlunya penembahan runway menjadi $2600 \mathrm{~m}$, taxiway 152 x 15 m, dan pelebaran untuk apron 105 x 67 m. Hasil desain terlampir.

Kata kunci: PengembanganBandarUdara, Runway, Taxiway,Apron

(C) 2018PenerbitFakultas Teknik Unkhair. All rights reserved 


\subsection{PENDAHULUAN}

Transportasi merupakan perpindahan manusia atau barang dari satu tempat ke tempat lainnya dengan menggunakan sebuah kendaraan yang digerakkan oleh manusia atau mesin. Di dalam pengertian transportasi tersebut, terdapat unsur-unsur yang terkait erat dalam berjalannya konsep transportasi itu sendiri. Unsur-unsur dalam transportasi tersebut yaitu, Manusia yang di butuhkan, Barang yang dibutuhkan, kendaraan sebagai alat, jalan dan terminal sebagai prasarana,dan organisasi (pengelola). Transportasi sendiri dibagi 3 yaitu transportasi darat, laut, dan udara.

Transportasi udara merupakan alat angkutan mutakhir dan tercepat. Transportasi ini menggunakan pesawat udara sebagai alat angkutan sedangkan udara atau angkasa sebagai jalur atau jalannya. Dimana pesawat udara Yang dimaksud dilengkapi dengan navigasi dan alat telekomunikasi yang canggih. Transportasi udara dapat menjangkau tempat - tempat yang tidak dapat ditempuh dengan transportasi darat atau transportasi laut. Bandara udara beserta segala aktivitasnya merupakan salah satu sarana dan prasana di dalam system transportasi udara, sebagai salah satu pilihan yang digunakan oleh masyarakat untuk keperluan perpindahan dari tempat asal ke tempat tujuan dan atau dipergunakan sebagai sarana dan prasarana pengangkutan barang dari satu tempat ke tempat lain.

Secara geo-strategis, Halmahera terletak pada jalur Internasional. Persilangan perdagangan yang sangat strategis. Jalur Australia-Timor Leste - Filipina dan sebaliknya. Kondisi demikian secara strategis jika mampu dimanfaatkan dengan baik maka akan memperbesar PAD daerah. Halmahera Timur secara umum menyimpan potensi yang sangat kuat. Kabupaten ini juga menyimpan kekayaan bahan tambang. Salah satu komoditi yang menjadi unggulan yaitu Nikel. Ada tiga sumber tambang nikel di Halmahera Timur, yakni Mabapura, Buli, dan Pulau Pakal. Karena adanya perusahaan tambang yang beroperasi menyebabkan intensitas arus penumpang pesawat di Bandara Buli semakin meningkat. Namun, dengan meningkatnya arus penumpang maka perlu adanya pengembangan di masa mendatang. Maka, Perluasan bandara dan perpanjangan run-way harus di lakukan agar lebih banyak alternatif jenis pesawat dapat mendarat.

Bandar Udara Buli terletak di Desa Pekaulang Buli Kab.Halmahera Timur yang berjarak $\pm 10 \mathrm{Km}$ dari Kota. Bandar Udara Buli memiliki dimensi existing runway $1200 \mathrm{~m}$ x $23 \mathrm{~m}$, dengan kondisi exsisting tersebut pelayanan penerbangan Bandar Udara Buli saat ini menggunakan pesawat jenis ATR 72-600 (Wings Air) dengan rute penerbangan Buli - Ternate dan Ternate - Buli. Namun dengan jenis pesawat tersebut dirasa kurang mencukupi untuk mobilitas penumpang angkutan udara yang akan datang maka direncanakan pesawat boeing 737-500 dengan jumlah kapasitas tempat duduk yang lebih dari 100 memungkinkan kebutuhan penumpang yang akan datang bisa terpenuhi.

Pemerintah Pusat telah menetapkan 13 kawasan industri baru di luar pulau Jawa yang akan dikembangkan sebagai sentral pertumbuhan produktivitas nasional. Dari 13 kawasan itu, Buli di Halmahera Timur (Haltim) menjadi satu-satunya kawasan di Maluku Utara yang masuk dalam program tersebut.Berkaitan erat dengan pengembangan potensi ekonomi wilayah, pemerintah Kabupaten (Pemkab) Haltim pun tidak tinggal diam untuk menjemput bola. Sejumlah strategi perencanaan pun mulai disusun untuk mendukung percepatan menuju kawasan industri yang didesain menjadikan Buli sebagai sentra yang diharapkan mampu menyerap ribuan tenaga kerja itu.

Untuk perencanaan kawasan industri Buli, Pemkab Haltim telah menyusun Rencana Detail Tata Ruang (RDTR) Perkotaan Buli, yang mana pada 2015 sudah disiapkan. Beberapa program dan kegiatan strategis guna menunjang kawasan industri Buli yang telah disiapkan diantaranya melengkapi beberapa infrastruktur dasar pelayanan seperti penyediaan air bersih (sudah masuk tahapan finalisasi sambungan rumah) "Termasuk juga penyiapan usulan untuk membangun rumah susun (Rusun) yang nantinya bisa dipergunakan oleh para pekerja di kawasan industri Buli yang bersifat disewakan secara murah,"

Selain itu, Pemkab sendiri, telah berkoordinasi dengan Kementerian Perindustrian (Kemenperin), untuk mengalokasi program kegiatan fasilitas sarana Balai Latihan Kerja (BLK) sebagai media pelatihan kerja) yang sudah masuk dalam usulan prioritas di Kemenperin untuk kegiatan 2017 di Buli. "Penambahan daya listrik masuk juga dalam perencanaan, tetapi itu akan sejalan dengan tahapan pembangunan pabrik Feni dan Nittera," imbuhnya.

\subsection{METODE PENELITIAN}

Metode yang digunakan adalah studi literatur, studi literatur ini adalah untuk mengumpulkan referensi teori yang dipakai sebagai bahan untuk menyusun dan menganalisa dalam penelitian ini.

\subsection{Tahap Pengumpulan Data}

1. Tahap I ( TahapPersiapan) 
Membuat surat permohonan pengambilan data di instansi terkait yaitu Kantor Bandar Udara Buli Kab.Halmahera Timur, Kantor BMKG Kab. Halmahera Timur, Kantor BPS Kab. Halmahera Timur, serta surat permohonan izin melakukan penelitian di lokasi studi. Tahap ini juga diikuti dengan pengumpulan referensi yang berhubungan dengan penelitian ini, yaitu :

1. Pengumpulan data

Data yang diperoleh dari pihak-pihak terkait untuk melengkapi dan mempermudah proses pelaksanaan penelitian, diantaranya :

1) Data penumpang untuk saat ini dan lima tahun kebelakang

2) Data angin

3) Data temperatur

4) Data elevasi

5) Data slope

6) Data karakteristik pesawat

7) Data existing Bandar udara Buli Maba

8) Data jumlah penduduk untuk saat ini dan lima tahun kebelakang

2. Dari data hasil penelitian dilapangan, selanjutnya dapat melakukanperhitungan untuk Bandar udara Buli Kab.Halmahera Timur.

\subsection{HASIL DAN PEMBAHASAN}

\subsection{Peramalan Pertumbuhan Lalu Lintas}

Untuk membuat suatu keputusan yang akan dilakukan di masa yang akan datang berdasarkan deret waktu diperlukan suatu metode permalan yang paling baik dalam memilih trend terbaik dengan menggunakan SSE (Sum of Square Error) sehingga memiliki nilai kesalahan (error) yang cenderung kecil.

Tabel 3.1 Tabel untuk menentukan trend terbaik pada penumpang berangkat

\begin{tabular}{|c|c|c|}
\hline e linear & e kuadratis & e eksponensial \\
\hline 36100 & 2916 & 35288.013 \\
\hline 39920.04 & 17371.24 & 39662.370 \\
\hline 4173.16 & 5097.96 & 3920.063 \\
\hline 985.96 & 1339.56 & 872.081 \\
\hline 11193.64 & 912.04 & 11250.988 \\
\hline 92372.8 & 27636.8 & 90993.515 \\
\hline
\end{tabular}

Dipilih nilai e kuadratik 27636.8 karna memiliki jumlah error yang lebih sedikit di bandingkan trend lainnya. Jadi Peramalan Penumpang Datang Menggunakan Regresi kuadratik.

Tabel 3.2 Pergerakan Penumpang Berangkat 2018-2032

\begin{tabular}{|c|c|c|}
\hline Tahun & $Y$ & $X$ \\
\hline 2013 & 17611 & -2 \\
\hline 2014 & 17383 & -1 \\
\hline 2015 & 17680 & 0 \\
\hline 2016 & 17875 & 1 \\
\hline 2017 & 18174 & 2 \\
\hline 2018 & 18706 & 3 \\
\hline 2019 & 19344 & 4 \\
\hline 2020 & 20118 & 5 \\
\hline 2021 & 21027 & 6 \\
\hline 2022 & 22073 & 7 \\
\hline 2023 & 23255 & 8 \\
\hline 2024 & 24573 & 9 \\
\hline
\end{tabular}




\begin{tabular}{|c|c|c|}
\hline Tahun & Y & X \\
\hline 2025 & 26027 & 10 \\
\hline 2026 & 27616 & 11 \\
\hline 2027 & 29342 & 12 \\
\hline 2028 & 31204 & 13 \\
\hline 2029 & 33202 & 14 \\
\hline 2030 & 35336 & 15 \\
\hline 2031 & 37605 & 16 \\
\hline 2032 & 40011 & 17 \\
\hline
\end{tabular}

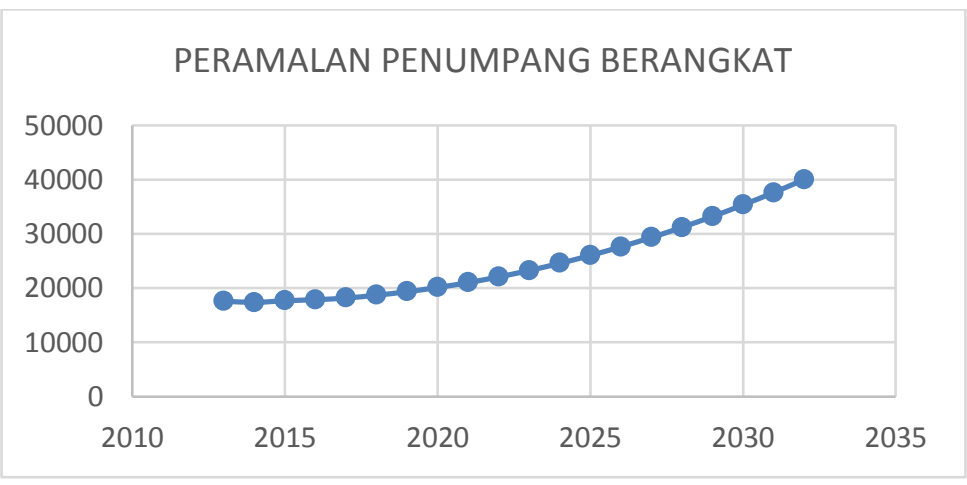

Gambar 3.1 Diagram pergerakan penumpang 2018-2032

Tabel 3.3 Untuk Memilih Trend terbaik

\begin{tabular}{|c|c|c|}
\hline e linear & e kuadratis & e eksponensial \\
\hline 56834.56 & 595.36 & 54894.160 \\
\hline 31969.44 & 5155.24 & 31783.929 \\
\hline 21025 & 4761 & 20136.369 \\
\hline 16179.84 & 408.04 & 15275.601 \\
\hline 45198.76 & 1.96 & 46062.104 \\
\hline 171207.6 & 10921.6 & 168152.163 \\
\hline
\end{tabular}

Dipilih nilai e kuadratik 10921 karna memiliki jumlah error yang lebih sedikit di bandingkan trend lainnya. Jadi Peramalan Penumpang Datang Menggunakan Regresi kuadratik.

Tabel 3.4 Pergerakan Penumpang Datang 2018-2032

\begin{tabular}{|c|c|c|}
\hline Tahun & Y & $X$ \\
\hline 2013 & 16521 & -2 \\
\hline 2014 & 16291 & -1 \\
\hline 2015 & 16512 & 0 \\
\hline 2016 & 16717 & 1 \\
\hline 2017 & 17244 & 2 \\
\hline 2018 & 17968 & 3 \\
\hline 2019 & 18904 & 4 \\
\hline 2020 & 20054 & 5 \\
\hline 2021 & 21418 & 6 \\
\hline 2022 & 22996 & 7 \\
\hline 2023 & 24789 & 8 \\
\hline
\end{tabular}




\begin{tabular}{|c|c|c|}
\hline Tahun & Y & X \\
\hline 2024 & 26795 & 9 \\
\hline 2025 & 29015 & 10 \\
\hline 2026 & 31449 & 11 \\
\hline 2027 & 34097 & 12 \\
\hline 2028 & 36960 & 13 \\
\hline 2029 & 40036 & 14 \\
\hline 2030 & 43326 & 15 \\
\hline 2031 & 46830 & 16 \\
\hline 2032 & 50548 & 17 \\
\hline
\end{tabular}

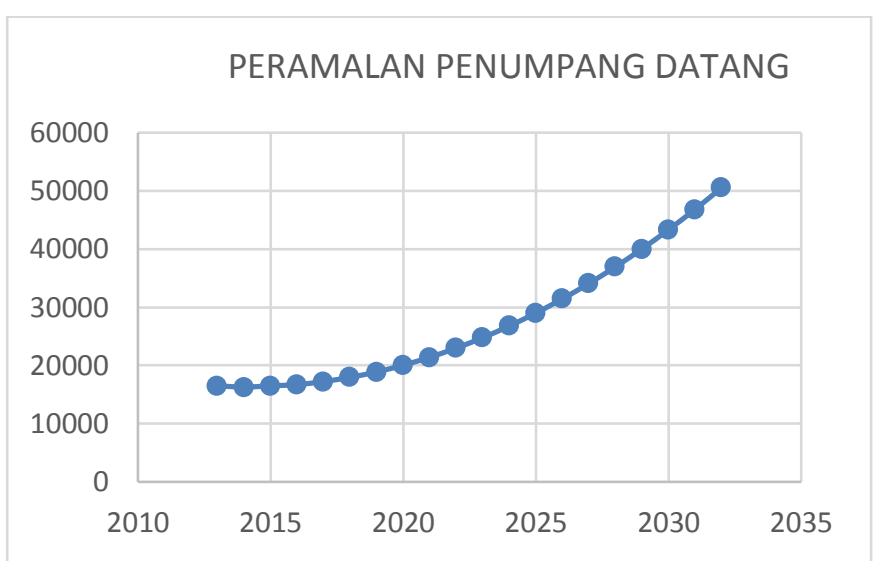

Gambar 3.2 Diagram pergerakan penumpang 2018-2032

\subsubsection{Perhitungan proyeksi pesawat}

Untuk membuat suatu keputusan yang akan dilakukan di masa yang akan datang berdasarkan deret waktu diperlukan suatu metode permalan yang paling baik dalam memilih trend terbaik dengan menggunakan SSE (Sum of Square Error) sehingga memiliki nilai kesalahan (error) yang cenderung kecil.

Tabel 3.5 Untuk Memilih Trend Terbaik

\begin{tabular}{|c|c|c|}
\hline E linear & E kuadratis & E eksponensial \\
\hline 14.44 & 0.04 & 14.71 \\
\hline 0.16 & 2.56 & 0.10 \\
\hline 57.76 & 12.96 & 56.49 \\
\hline 1.44 & 10.24 & 1.48 \\
\hline 9.00 & 1.00 & 8.34 \\
\hline 82.80 & 26.80 & 81.10 \\
\hline
\end{tabular}

Dipilih nilai e kuadratik 26.80 karna memiliki jumlah error yang lebih sedikit di bandingkan trend lainnya. Jadi Peramalan Pesawat Datang Menggunakan Regresi kuadratik.

Tabel 3.6Pergerakan Pesawat 2018-2032

\begin{tabular}{|c|c|c|}
\hline Tahun & Y & $X$ \\
\hline 2013 & 382 & -2 \\
\hline 2014 & 373 & -1 \\
\hline 2015 & 361 & 0 \\
\hline
\end{tabular}




\begin{tabular}{|c|c|c|}
\hline Tahun & Y & X \\
\hline 2016 & 365 & 1 \\
\hline 2017 & 362 & 2 \\
\hline 2018 & 368 & 3 \\
\hline 2019 & 377 & 4 \\
\hline 2020 & 391 & 5 \\
\hline 2021 & 408 & 6 \\
\hline 2022 & 429 & 7 \\
\hline 2023 & 454 & 8 \\
\hline 2024 & 483 & 9 \\
\hline 2025 & 517 & 10 \\
\hline 2026 & 554 & 11 \\
\hline 2027 & 595 & 12 \\
\hline 2028 & 640 & 13 \\
\hline 2029 & 689 & 14 \\
\hline 2030 & 743 & 15 \\
\hline 2031 & 800 & 16 \\
\hline 2032 & 861 & 17 \\
\hline
\end{tabular}

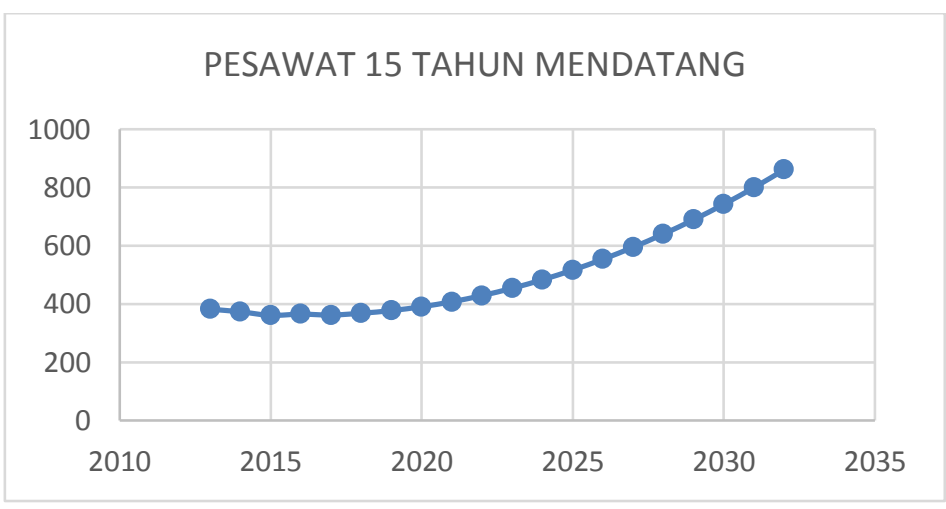

Gambar 3.3Diagram pergerakan pesawat 2018-2032

\section{* Pergerakan Pesawat Pada Jam Sibuk}

Jumlah pergerakan yang didapat data berupa volume tahunan, dimana volume tahunan merupakan akumulasi dari volume tiap jam dengan nilai yang bervariasi. Dalam data tahunan terdapat nilai maksimum dari tiap bulan hingga tiap jam. Nilai maksimum ini merupakan jumlah pergerakan pesawat dan penumpang terbanyak yang dicapai dalam 1 jam atau 60 menit.

Dari data pergerakan tahunan akan disesuaikan menjadi data pada jam puncak. Proses penyesuaian ini akan menghasilkan data pergerakan pesawat pada jam sibuk. Untuk mendapatkan volume jam puncak maka perlu melakukan perhitungan terhadap volume pergerakan pesawat untuk keberangkatan.

Perhitungan jam puncak dihitung pertahun guna mendapatkan kebutuhan panjang runway. Sebagai contoh perhitungan di bawah ini data yang digunakan adalah pergerakan pesawat pada tahun 2032 dengan pesawat Boeing 737-500.

$$
\text { a. } \begin{aligned}
\mathrm{Md} & =\frac{M y}{365} \\
\mathrm{Md} & =\frac{861}{365} \\
\mathrm{Md} & =2.36=2 \text { pergerakan }
\end{aligned}
$$


Dimana :

$$
\begin{aligned}
\text { b. } & \mathrm{Cp}=\frac{1,38}{\sqrt{M d}} \\
\mathrm{Cp} & =\frac{1,38}{\sqrt{2}} \\
\mathrm{Cp} & =0.899 \\
\text { c. } \quad & \mathrm{Mp}=\mathrm{Md} \times \mathrm{Cp} \\
& \mathrm{Mp}=2 \times 0.899 \\
\mathrm{Mp} & =2.120=2 \text { pergerakan }
\end{aligned}
$$

Cp : Faktor jam puncak

Md : Pergerakan pesawat harian

Mp : Pergerakan pesawat pada jam sibuk

My : Pergerakan pesawat tahunan

\subsection{Perencanaan Sisi Udara}

Dengan mengacu pada Aerodrome Reference Code pada ICAO Annex-14 Aerodromes, garis besar perencangan ini adalah meningkatkan kelas bandara dari $3 C$ ke $4 C$ dilihat dari pesawat terbesar yang bisa dilayani Bandar Udara Buli saat ini dan rencana kedepannya. Perencanaan sisi udara meliputi runway, taxiway, dan apron. Perencanaan sisi udara dipengaruhi oleh jenis pesawat terbesar yang mendarat di Bandar Udara Buli dan jenis yang dipakai adalah Boeing 737-500. Berikut data-data penunjang dalam perencanaan :

a. Data lokasi bandar udara

$$
\begin{aligned}
& \text { Elevasi Bandar udara Buli }: 1.57 \mathrm{~m} \\
& \text { Kemiringan landasan }: 1 \%
\end{aligned}
$$

Temperature harian rata-rata dalam bulan terpanas $: 26,84{ }^{\circ} \mathrm{C}$

Harian terpanas pada bulan itu $\quad: 27,2^{\circ} \mathrm{C}$

Kecepatan angin rata-rata : 11 knots

Kelembaban rata-rata: $27,30 \%$

b. Data pesawat rencana

Pesawat rencana : Boeing 737-500

Bentang sayap : $: 28.9 \mathrm{~m}$

Panjang pesawat $\quad: 31 \mathrm{~m}$

Jarak roda $\quad: 11.38 \mathrm{~m}$

Jarak antar roda pendaratan $\quad: 5.23 \mathrm{~m}$

Berat lepas landas struktur maksimum : $60500 \mathrm{~kg}$

Berat pendaratan maksimum $\quad: 49900 \mathrm{~kg}$

Berat bahan bakar $\quad: 46720 \mathrm{~kg}$

Panjang landasan $\quad: 2286 \mathrm{~m}$

Jumlah maksimum penumpang $\quad$ : 140 orang

* Perencanaan Landas Pacu (Runway

a. Panjang landas pacu

Panjang landas pacu yang diperlukan (Aeroplane Reference Field Length/ARFL) telah ditentukan oleh setiap pabrik pembuat pesawat ARFL untuk pesawat Boeing 737-500 adalah 2286 m, tetapi masih harus dikoreksi terhadap beberapa faktor sebagai berikut

1. Koreksi terhadap elevasi 
Elevasi Bandar Udara Buli $(h)=1.57 \mathrm{~m}$.

Dapat dihitung faktor koreksi terhadap elevasi $(\mathrm{Fe})$.

$$
\begin{aligned}
& \mathrm{Fe}=1+\left[\mathbf{0 , 0 7} \times\left(\frac{\boldsymbol{h}}{\mathbf{3 0 0}}\right)\right] \\
& \mathrm{Fe}=1+\left[\mathbf{0 , 0 7} \times\left(\frac{\mathbf{1 . 5 7}}{\mathbf{3 0 0}}\right)\right] \\
& \mathrm{Fe}=1,00037 \text { meter }
\end{aligned}
$$

Panjang landasan akibat pengaruh elevasi adalah :

$\mathrm{Fe}=1,00037 \times 2.286=2.286,84$ meter

2. Koreksi terhadap temperature

Faktor koreksi temperatur (Ft) untuk memperhitungkan panjang runway terhadap temperatur sebesar $1 \%$ untuk setiap kenaikan $1{ }^{\circ} \mathrm{C}$. Untuk setiap kenaikan $1000 \mathrm{~m}$ dari permukaaan laut temperatur akan turun $6.5^{\circ} \mathrm{C}$, Temperatur di Bandar Udara Buli adalah $28.6^{\circ} \mathrm{C}$.

Dapat dihitung faktor kereksi terhadap temperature $(F t)$

$F t=1+(0,01 \times(T-(15-0,0065 \times h)))$

$F t=1+(0,01 \times(28.6-(15-0,0065 \times 1.57)))$

$F t=1,136$ meter

Panjang landasan akibat temperature adalah :

$F t \quad=1,136 \times 2.286,84=2.598 .081$ mete

3. Koreksi terhadap kemiringan landasan

Kemiringan Bandar udara Buli $(s)=1 \%$

Dapat dihitung faktor koreksi terhadap kemiringan (Fs)

$F s=1+0,1 \times S$

$F_{S}=1+0,1 \times 0,01$

$F_{S}=1,001 \mathrm{~m}$

Panjang landasan akibat pengaruh kemiringan landasan

$F s=1,001 \times 2.598,081=2.600,679 m \approx 2.601$ meter

Panjang runway setelah dilakukan koreksi terhadap elevasi, temperatur dan kemiringan maka diambil 2.601. Panjang ini merupakan panjang minimum yang harus dipenuhi dan demi kenyamanan serta peningkatan keselamatan, direncanakan panjang landasan pacu $2.600 \mathrm{~m}$. Panjang tersebut memenuhi ketegori panjang runway kode angka 4 yaitu > $1800 \mathrm{~m}$. Dengan panjang runway eksisting yaitu $1.500 \mathrm{~m}$, sehingga penambahan panjang runway yang dibutuhkan adalah $2.600-1.500=1.100 \mathrm{~m}$ agar dapat didarati pesawat jenis Boeing 737500.

b. Perencanaan lebar landas pacu

Berdasarkan persyaratan ICAO dalam Annex-14 Aerodromes, lebar runway untuk bandara dengan kodehuruf $C$ tidak boleh kurang dari 45 m.Dengan lebar runway eksisting bandara sebesar $30 \mathrm{~m}$, maka dibutuhkan penambahan lebar sebesar 45-30 = $15 \mathrm{~m}$.

* Perencanaan Landas Hubung (Taxiway)

Dalam suatu perencanaan landas hubung (taxiway) dapat dihitung panjang dan lebar sesuai dengan jenis pesawat rencana dimana dipilih pesawat dengan jenis Boeing 737-500.

a. Perencanaan panjang landas hubung (taxiway)

Pesawat rencana yang digunakan di Bandar Udara Buli adalah pesawat jenis Boeing 737-500 sesuai dengan Aerodrome Reference Code yang dikeluarkan ICAO untuk ARFL > $1800 \mathrm{~m}$, mempunyai kode angka 4 dan kode huruf $C$. 
Pendekatan rumus yang digunakan untuk perhitungan panjang taxiway adalah

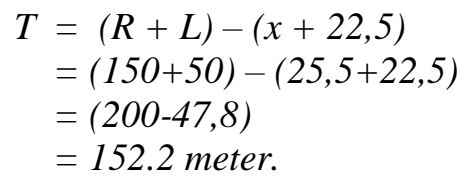

Keterangan :

$T:$ Panjang taxiway

$R$ : Lebar runway strip yaitu $150 \mathrm{~m}$.

L: Jarak dari tepi runway strip sampai ekor pesawat yaitu $50 \mathrm{~m}$.

$x$ : Lebar ruang bebas dibelakang ekor pesawat, yang merupakan total dari

a. Lebar Clerance diambil $=11 \mathrm{~m}$

b. lebar 0,5 $x$ wing span $=14,5 \mathrm{~m}$ maka $x=25,5 \mathrm{~m}$

Dari perhitungan diatas maka panjang taxiway adalah 152.2 meter.

Kebutuhan panjang taxiway, dengan pesawat Boeing 737-500 adalah $152.2 \mathrm{~m}$. Dengan kondisi eksiting panjang taxiway Bandar Udara Buli sebesar $75 \mathrm{~m}$, maka perlu dilakukan pelebaran taxiway.

b. Perancangan lebar landas hubung (taxiway)

Sesuai standar yang ditetapkan oleh ICAO dalam Annex-14 Aerodromes untuk B 737-500 mempunyai kode huruf $C$ maka ditentukan lebar taxiway adalah tidak kurang dari 15 m, maka sesuai dengan kondisi eksisting Bandar udara Buli yang juga memiliki lebar $15 \mathrm{~m}$ sudah memenuhi syarat dan dapat dilewati oleh pesawat jenis Boeing 737-500.

- Perancangan Landas Parkir (Apron)

Data eksisiting Bandar Udara Buli adalah sebagai berikut:
1. Panjang
$=60 \mathrm{~m}$
2. Lebar
$=40$
3. Luas
$=(60 \times 40) \mathrm{m}^{2}$
4. Konstruksi Lapisan permukaan
$=$ Asphalt Hotmix

Dengan pesawat rencana jenis Boeing 737-500 dan termasuk dalam Aerodrome Refence Code termasuk pada letter code C. Apron harus ditempatkan sedemikian rupa sehingga pesawat terbang yang akan diparkir ditempat tersebut tidak akan menabrak Obstancle limitation surface dan khususnya permukaan transisi (transional surface). Aircrafct parking position taxilaen harus dipisahkan dari sebarang objek dengan jarak tidak kurang dari yang di tetapkan. Bandar Udara Buli dengan Aerodrome Reference Code termasuk pada letter code $C$ memiliki jarak garis tengah Aircrafct parking position taxilane ke objek sebesar 24,5 meter dan jarak dari ujung sayap pesawat terbang pada posisi parkir pesawat terbang (Aircrafct parking position) ke objek sebesar 4,5 meter

a. Perhitungan panjang apron

Dengan pesawat rencana jenis Boeing 737-500 yang memiliki bentang sayap sebesar 28,9 meter (Aircrafct parking position) ke objek lain 4,5 meter. Dengan demikian panjang minimum apron yang dibutuhkan untuk mengetahui jumlah pesawat rencana yang dapat di parkir sebagai berikut :

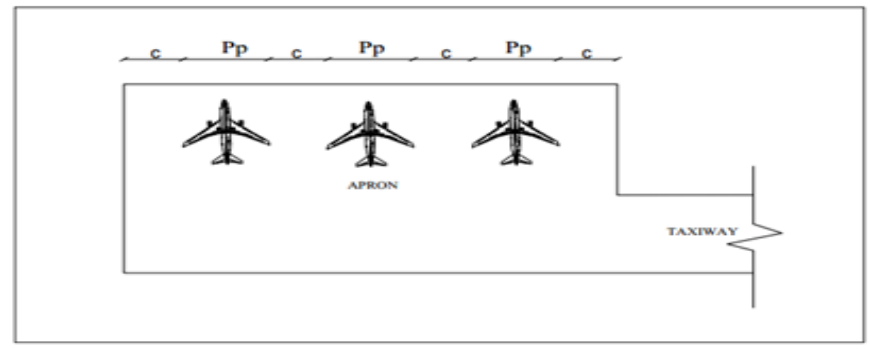

Gambar 3.4 Perhitungan Panjang Apron 
Direncana pesawat yang parkir 3 buah pesawat Boeing 737-500

$$
\begin{aligned}
\text { Panjang apron } & =(3 \times \mathrm{Pp})+(4 \times \mathrm{c}) \\
& =(3 \times 28,9)+(5 \times 4,5) \\
& =104.7 \text { meter }
\end{aligned}
$$

Jadi kebutuhan panjang apron untuk pengembangan adalah 104.7 meter, lebih besar daripada panjang apron eksisting 60 meter perlu di perpanjang 45 meter. Maka direncanakan panjang apron sebesar 105 meter.

\subsection{KESIMPULAN}

Perencanaan pengembangan Bandar Udara adalah salah satu perencanaan yang sangat unik karena belum tentu dapat di prediksi berdasarkan angka-angka yang ada, banyak faktor-faktor pendukung lain yang mempengaruhi pengembangan sebuah Bandar Udara. Dalam hal ini penyusun menggunakan beberapa asumsi yang bersifat numeris dalam merencanakan pengembangan Bandar Udara Buli Kab. Halmahera Timur.

Berdasarkan hasil analisis, didapatkan kesimpulan sebagai berikut :

a. Berdasarkan data yang tersedia lima tahun kebelakang dapat di olah untuk perkiraan penumpang 15 tahun yang akan datang sehingga diperoleh hasil yaitu pada tahun 2032 perkiraan jumlah penumpang sebanyak 50548 orang dan penumpang per hari sebanyak 140 orang. Dan dari hasil analisis menggunakan metode Analisa Trend Linear, Eksponensial, dan Kuadratik maka di dapatkan frekuensi penerbangan pada tahun 2032 sebnyak 2 kali penerbangan dengan menggunakan pesawat rencana B 737-500

b. Sisi udara

1. Runway

Runway mengalami pertambahan dimensi panjang 1100 meter yang semula $1500 \mathrm{~m}$ menjadi 2600 meter sedangkan lebar runway tidak boleh kurang dari 45 meter, dengan lebar eksisting 30 maka dubutuhkan pertambahan lebar sebesar 15 meter sehingga dapat didaratkan pesawat jenis terbesar Boeing $737-500$

2. Taxiway

Dimensi panjang Taxiway hasil analisi adalah 152.2 meter dan juga dimensi lebar 15 meter dengan sudut $45^{\circ}$, dengan dimensi yang ada sudah dapat dilewati pesawat jenis terbesar Boeing $737-500$

3. Apron

Kebutuhan panjang apron untuk pengembangan adalah 104.7 meter, lebih besar daripada panjang apron eksisting 60 meter perlu di perpanjang 45 meter. Maka direncanakan panjang apron sebesar 105 meter dan kebutuhan lebar apron untuk pengembangan adalah 67 meter, lebih besar daripada lebar apron eksisting 40 meter. Maka direncanakan lebar apron sebesar 67 meter, dapat diparkir 3 ( tiga ) pesawat

\section{References} jenis terbesar Boeing 737 - 500 dengan jenis parkir pararel parking.

[1] Basuki, Heru. 1986. Merancang, Merencana, LapanganTerbang, Alumni ITB Bandung.

[2] Hononjeff, R. 1975. Planning and desigh Of Airport, Second Edition, New York Mac GrawHill Book Company

[3] Hazanawati, 2008.KajianPengembanganSisiUdara Bandar Udara Japura Kabupaten Indragiri Hulu, JurusanTeknikSipildanLingkungan, FakultasTeknik,Universitas Gajah Mada

[4] Sartono. W. 2016. PengenalandanPerancanganGeometrik Runway, Taxiway, danApron

[5] Tim Penyusun, 2014, Profil DaerahKabupaten Halmahera Timur 2014, BP4D, Maba.

[6] Tim Penyusun, 2016, Rencana Pembangunan JangkaMenengah Daerah (RPJMD) Kabupaten Halmahera TimurTahun 2016 - 2021, BP4D, Maba.

[7] Tim Penyusun, 2010, Rencana Tata Ruang Wilayah (RTRW) Kabupaten Halmahera Timur 2010-2029,BP4D, Maba 